\title{
Article \\ Cognitive and Neural Mechanisms of Social Communication Dysfunction in Primary Progressive Aphasia
}

\author{
Zoë-Lee Goldberg ${ }^{1,2}$, Hashim El-Omar ${ }^{1,2}$ (), David Foxe ${ }^{1,2,3}$ () Cristian E. Leyton ${ }^{1,2}$, Rebekah M. Ahmed ${ }^{1,3,4}$, \\ Olivier Piguet ${ }^{1,2}$ and Muireann Irish $1,2, * \mathbb{D}$ \\ 1 Brain and Mind Centre, The University of Sydney, Sydney, NSW 2050, Australia; \\ zoe.goldberg@sydney.edu.au (Z.-L.G.); hashim.el-omar@sydney.edu.au (H.E.-O.); \\ david.foxe@sydney.edu.au (D.F.); cristian.leyton@sydney.edu.au (C.E.L.); \\ rebekah.ahmed@sydney.edu.au (R.M.A.); olivier.piguet@sydney.edu.au (O.P.) \\ 2 School of Psychology, The University of Sydney, Sydney, NSW 2006, Australia \\ 3 School of Medical Sciences, University of Sydney, Sydney, NSW 2006, Australia \\ 4 Memory and Cognition Clinic, Department of Clinical Neurosciences, Royal Prince Alfred Hospital, \\ Sydney, NSW 2050, Australia \\ * Correspondence: muireann.irish@sydney.edu.au; Tel.: +61-2-9114-4165
}

\section{check for} updates

Citation: Goldberg, Z.-L.; El-Omar, H.; Foxe, D.; Leyton, C.E.; Ahmed, R.M.; Piguet, O.; Irish, M. Cognitive and Neural Mechanisms of Social Communication Dysfunction in

Primary Progressive Aphasia. Brain Sci. 2021, 11, 1600. https://doi.org/ $10.3390 /$ brainsci11121600

Academic Editors:

Vasileios Papavasileiou

and Ana Maria Bugă

Received: 1 November 2021

Accepted: 29 November 2021

Published: 1 December 2021

Publisher's Note: MDPI stays neutral with regard to jurisdictional claims in published maps and institutional affiliations.

Copyright: (c) 2021 by the authors. Licensee MDPI, Basel, Switzerland. This article is an open access article distributed under the terms and conditions of the Creative Commons Attribution (CC BY) license (https:/ / creativecommons.org/licenses/by/ $4.0 /)$.

\begin{abstract}
Mounting evidence suggests that, in parallel with well-defined changes in language, primary progressive aphasia (PPA) syndromes display co-occurring social cognitive impairments. Here, we explored multidimensional profiles of carer-rated social communication using the La Trobe Communication Questionnaire (LCQ) in 11 semantic dementia (SD), 12 logopenic progressive aphasia (LPA) and 9 progressive non-fluent aphasia (PNFA) cases and contrasted their performance with 19 Alzheimer's disease (AD) cases, 26 behavioural variant frontotemporal dementia (bvFTD) cases and 31 healthy older controls. Relative to the controls, the majority of patient groups displayed significant overall social communication difficulties, with common and unique profiles of impairment evident on the LCQ subscales. Correlation analyses revealed a differential impact of social communication disturbances on functional outcomes in patient and carer well-being, most pronounced for SD and bvFTD. Finally, voxel-based morphometry analyses based on a structural brain MRI pointed to the degradation of a distributed brain network in mediating social communication dysfunction in dementia. Our findings suggest that social communication difficulties are an important feature of PPA, with significant implications for patient function and carer well-being. The origins of these changes are likely to be multifactorial, reflecting the breakdown of fronto-thalamic brain circuits specialised in the integration of complex information.
\end{abstract}

Keywords: social cognition; language; frontotemporal dementia; Alzheimer's disease; thalamus; frontal lobe

\section{Introduction}

Primary progressive aphasia (PPA) refers to a collection of diverse neurodegenerative clinical syndromes characterised by progressive deterioration of language and speech functions. Current diagnostic criteria recognise three PPA variants based on distinct profiles of linguistic changes, distribution of brain atrophy and underlying neuropathology [1]. These variants are semantic variant PPA (referred to here as semantic dementia (SD)), nonfluent/agrammatic variant PPA (or progressive non-fluent aphasia (PNFA)) and logopenic variant PPA (or logopenic progressive aphasia (LPA)), each of which is characterised by differential patterns of language and motor speech dysfunction. SD is defined by the progressive loss of conceptual knowledge, which impairs both receptive and produced language in the context of relatively intact fluency, phonology, and syntax. Impoverished language is also a prototypical feature of LPA, manifesting in slowing of spontaneous speech, phonological errors and paraphasias, sentence repetition and word-finding difficul- 
ties. Finally, PNFA is typified by the progressive disruption of language fluency, resulting in hesitant, distorted speech and diminished grammatical complexity.

Over the past decade, significant progress has been made in understanding the variable profiles of language and motor speech dysfunction exhibited by PPA syndromes as well as their potential neuroanatomical and pathological signatures (reviewed by $[2,3]$ ). Despite such advances, it remains challenging to differentiate between PPA variants in the clinical setting, resulting in delayed diagnosis and poor patient prognosis [4-6]. This challenge, in part, reflects the fact that in parallel with well-defined changes in language, PPA syndromes frequently present with co-occurring non-linguistic cognitive deficits $[7,8]$. While these non-linguistic cognitive deficits are generally proposed to scale with disease severity, mounting evidence suggests highly variable and overlapping cognitive profiles, independent of primary language dysfunction [9]. One domain that has received increasing attention in this regard is that of social cognition [10].

Changes in social and interpersonal function are increasingly recognised as early features of PPA that can be intertwined with or independent from the canonical linguistic and motor speech changes in these syndromes. Mounting evidence points to marked socioemotional disturbances across the majority of PPA variants, with the suggestion that many of these symptoms emerge in parallel with, and not secondary to, their language and speech production difficulties (reviewed by [10]). A growing literature indicates striking impairments in emotion processing in PPA [11-14], although mixed findings have been reported in relation to LPA [15]. Similarly, theory-of-mind impairments are now understood to emerge as a standalone feature in SD [16,17] and PNFA [18], while diminished capacity for empathy is also widely observed in PPA syndromes $([13,19,20]$, but see [21]). This co-occurrence of social cognitive and language disturbances in PPA has important implications in terms of functional outcomes for patients, as it can further affect the ability to communicate meaningfully, and may disrupt the capacity to form and sustain interpersonal relationships [22].

In this context, pragmatics represent an important aspect of communication to explore. Pragmatics refers to the use of natural language, in terms of literal and non-literal aspects of communicated meaning, within particular interactional contexts [23,24]. To bridge the gap between what is said and what is actually meant, pragmatics are posited to require some form of inferential process and thus are viewed as essential to social communication [25]. Social communication refers to the use of language in social contexts and relies on attuning one's linguistic behaviour and intent to the specific demands of a given context, inferring the speaker's intended meaning to provide the appropriate information and engaging in an array of coordination processes, including turn-taking, topic maintenance and terminating at the appropriate juncture [26]. The multifaceted nature of social communication has been suggested to draw upon a distributed brain network, comprising distinct dorsomedial prefrontal, anterior temporal and inferior parietal cortices, and their respective connections, to coordinate the representation of informative actions, communicative intentions, processing of lexical/semantic information, syntactic analysis and pragmatic integration [27]. Importantly, many of these regions harbour brain atrophy from early in the PPA disease course, suggesting that social communication would be deleteriously affected in these disorders. Despite some evidence of decline in pragmatics in healthy aging [28] and mild cognitive impairment (MCI; [29]), it remains unclear how social communication is affected in PPA or neurodegenerative disorders more broadly.

The objectives of the current study were threefold. First, we sought to characterise the nature of social communication dysfunction across PPA syndromes (SD, LPA, PNFA) using a validated tool, the La Trobe Communication Questionnaire (LCQ; [30]), and to contrast profiles of impairment in PPA with that of Alzheimer's disease (AD) and the behavioural variant of frontotemporal dementia (bvFTD), two dementia disorders in which language and socioemotional functions are differentially impacted [31-33]. Second, given that pragmatic disruption in clinical disorders is associated with negative effects on social relationships and quality of life [34], we sought to establish the impact of social 
communication dysfunction on patient functional outcomes and carer well-being. Finally, to provide a comprehensive understanding of the neurobiology of social communication, we conducted voxel-based morphometry analyses on structural brain scans to determine the neural signature of social communication dysfunction using a transdiagnostic approach.

Given the profound nature of language and motor speech difficulties in PPA, we hypothesised that social communication disturbances as measured by the overall score on the LCQ would be present across the majority of PPA syndromes. Importantly, we predicted that distinct profiles of social communication would be evident across the LCQ subscales and that the severity of social communication dysfunction would scale with the overall level of functional impairment in patients and the degree of burden reported by carers. Finally, in terms of underlying neural substrates, we predicted that the severity of social communication dysfunction would correlate with the magnitude of atrophy in frontoparietal brain regions implicated in speech, language, and social inference [27].

\section{Materials and Methods}

\subsection{Participants}

A total of 108 participants took part in this study, of which 12 patients with a clinical diagnosis of logopenic progressive aphasia (LPA), 11 patients diagnosed with semantic dementia (SD; 4 cases with right-sided SD) and 9 patients diagnosed with progressive non-fluent aphasia (PNFA) [1] were contrasted with 19 clinically probable Alzheimer's disease (AD) [35] and 26 clinically probable behavioural-variant frontotemporal dementia (bvFTD) [36] cases. A comparison group of 31 healthy older controls was recruited. All participants were seen through the FRONTIER frontotemporal dementia research group in Sydney, Australia. Diagnoses were established by multidisciplinary consensus between a senior neurologist (RMA), a clinical neuropsychologist and an occupational therapist in line with current consensus criteria. All participants underwent comprehensive clinical investigation and neuropsychological assessment along with structural neuroimaging. Disease duration was estimated using years elapsed since reported onset of symptoms. Disease staging was determined using the Frontotemporal Dementia Functional Rating Scale (FRS) [37], a dementia staging tool sensitive to changes in functional abilities, activities of daily living and behavioural symptoms. Carers rated their own perceived levels of burden using the Zarit Burden Interview (ZBI) [38].

Exclusion criteria for all participants included prior history of stroke, epilepsy, alcohol and other drug abuse, significant traumatic brain injury, other primary neurological, psychiatric or mood disorders and limited English proficiency.

Ethics approval for this study was granted by the University of New South Wales and the South Eastern Sydney Local Health District human ethics committee. All participants, or the persons responsible for them, provided written informed consent in accordance with the Declaration of Helsinki. Participants were provided with information sheets and consent forms in advance of their research appointment to provide time to review the study aims and seek clarification on any aspects of the proposed research. On the day of testing, the information sheets and consent forms were reviewed again in person with a member of the research team to allow further opportunity for questions and discussion.

\subsection{Cognitive Screening}

Global cognitive functioning was determined using Addenbrooke's Cognitive Examination, Third Edition (ACE-III; [39,40]), a test of cognitive function covering attention, memory, verbal fluency, language, and visuospatial abilities. In addition, participants completed a comprehensive battery of neuropsychological tests assessing integrity of the main cognitive domains. Attention was assessed using Digit Span forwards [41]. Executive function was measured using the Trail Making Test (Part B-A) [42], while non-verbal episodic memory was assessed using the Rey Complex Figure [43], from which we calculated a percentage retained score $(3 \mathrm{~min}$ recall/Copy $\times 100)$ (see also [44]). Language ability was assessed using the naming, comprehension, semantic association and single-word 
repetition subtests of the Sydney Language Battery (SYDBAT; [45]). Finally, inhibitory control was measured using the Hayling Sentence Completion Test [46].

\subsection{Assessment of Social Communication Profiles}

Social communication deficits were examined using the La Trobe Communication Questionnaire (LCQ [30]). The LCQ is a 30-item questionnaire comprising statements relating to the frequency of social communication deficits in everyday life, for example, "When talking to others how frequently does s/he hesitate, pause or repeat themselves?" Carers rated the social communication profiles of patients, while controls completed a self-rated version of the questionnaire. A 4-point Likert scale was used to rate the frequency of behaviours (1, never; 2 , sometimes; 3 , often; 4 , always), allowing for a total possible score of 120 , with higher scores indicating greater perceived social communication deficits.

The LCQ further permits the assessment of social communication across 4 discrete subdomains: Initiation/Conversational flow, relating to initiating and maintaining conversation; Disinhibition/Impulsivity, pertaining to rude, embarrassing or inappropriate conversational attributes; Conversational Effectiveness, relating to logical, accurate and reciprocal conversation; and Partner Sensitivity, based on Gricean maxims of quality and quantity, i.e., communicative principles by which the quality and quantity of communication are as informative and effective as possible (see [47] for full details).

\subsection{Statistical Analyses}

Behavioural data were analysed using IBM SPSS Statistics (version 26). Prior to analyses, Shapiro-Wilks tests were used to check for normality of distributions across the variables of interest. Demographic and neuropsychological variables were investigated using one-way analysis of variance (ANOVA). Chi-squared tests were used to explore group differences in categorical variables (e.g., sex). A univariate analysis of variance (ANOVA) was used to investigate the main effects of groups (LPA, SD, PNFA, AD, bvFTD, controls) for total LCQ, while a multivariate ANOVA (MANOVA) was used to explore group effects across the LCQ subscales, followed by Sidak or Games-Howell post hoc tests as appropriate. Effect sizes for significant findings at $p<0.05$ were reported using partial eta squared $\left(\eta_{p}{ }^{2}\right)$. One-tailed Pearson's R correlations were used to explore associations between total LCQ performance and relevant clinical and neuropsychological variables.

\subsection{Image Acquisition}

Participants underwent whole-brain $\mathrm{T}_{1}$-weighted structural neuroimaging using a 3T Phillips MRI scanner with a standard quadrature head coil (eight channels). The 3D $\mathrm{T}_{1}$-weighted images were acquired via the following scanning sequences: coronal orientation, matrix $256 \times 256,200$ slices, $1 \mathrm{~mm}^{2}$ in plane resolution, slice thickness $=1 \mathrm{~mm}$, echo time $/$ repetition $=2.6 / 5.8 \mathrm{~ms}$ and flip angle $\alpha=8^{\circ}$. All scans were visually inspected for artefacts prior to analyses. Due to imaging contraindications (e.g., pacemaker, claustrophobia), structural scans were available for 7 LPA, 9 SD, 7 PNFA, 12 AD, 22 bvFTD and 22 controls (total imaging sample $n=79$ ).

\subsection{Voxel-Based Morphometry}

Structural MRI data were analysed via voxel-based morphometry analyses (VBM) using the FSL-VBM toolbox from the FMRIB software package $[48,49]$. This technique permits the identification of voxel-by-voxel changes in grey matter intensity across the entire brain. Briefly, structural MR images were extracted using the brain extraction tool (BET) [50], following which tissue segmentation was conducted using FMRIB's Automatic Segmentation Tool (FAST) [51]. The resultant grey matter partial volumes were then aligned to the Montreal Neurological Institute standard space (MNI52) via the FMRIB nonlinear registration tool (FNIRT) $[52,53]$ using a b-spline representation of the registration warp field [54]. A study-specific template was created in which LPA, SD, PNFA, AD, bvFTD and control participants were equally represented to which the native grey matter images 
were re-registered nonlinearly. To correct for local expansion or contraction, the registered partial volume maps were modulated by dividing by the Jacobian of the warp field. Finally, the modulated and segmented images were smoothed using an isotropic Gaussian kernel with a sigma of $3 \mathrm{~mm}$.

\subsection{Profiles of Grey Matter Atrophy}

Permutation-based non-parametric testing was used to investigate grey matter intensity differences between groups via an unbiased whole-brain general linear model [55] with 5000 permutations per contrast. Differences in cortical grey matter intensities between LPA, SD, PNFA, AD, bvFTD and Control participants were explored using regression models with separate directional contrasts (i.e., $t$-tests). Age was included as a nuisance variable in all contrasts. Clusters were extracted using the threshold free cluster enhancement method, corrected for family wise error (FWE) at $p<0.001$. These analyses confirmed characteristic profiles of grey matter intensity decrease in the patient groups relative to controls (see Supplementary Material for full details).

\subsection{Neural Substrates of Social Communication Changes}

Finally, correlation analyses were run to explore associations between social communication dysfunction, as indexed by the total LCQ score, and grey matter intensity decrease across the entire brain. For this analysis, all participants were considered together as a single group $(n=79)$ to explore brain-behaviour relationships irrespective of clinical diagnosis. A general linear model with a negative t-contrast was run to explore associations between grey matter intensity decrease and higher total LCQ scores. Age was included as a nuisance variable in all contrasts. To boost our power to detect meaningful signal, while controlling for false positives, we extracted clusters voxel-wise and corrected using a false discovery rate of $q=0.05$ [56]. This yielded a corrected $p$-value of 0.03 from the data. To further guard against false positives, statistical maps were thresholded using a strict cluster extent threshold of 50 contiguous voxels. Anatomical locations of statistical significance were overlaid on the MNI standard brain with maximum coordinates provided in the MNI stereotaxic space.

\section{Results}

\subsection{Demographic and Neuropsychological Data}

Table 1 displays background clinical and cognitive data for study participants. The participant groups did not differ in terms of age, sex, and education (all $p$-values $>0.16$ ); and patient groups did not differ significantly for disease duration (years elapsed since symptom onset). Group differences were observed for disease severity (FRS) with AD and bvFTD patients exhibiting greater functional impairment compared with the PNFA group ( $p$-values $<0.05$ ). Significant group differences were evident in the ACE-III total scores $\left(F(5,100)=15.701, p<0.0001, \eta_{p}^{2}=0.440\right)$, with LPA, SD, bvFTD and AD patient groups showing deficits in overall cognitive function relative to controls. No significant differences were observed in the ACE-III total between PNFA and Controls $(p=0.19)$. Games-Howell post hoc analyses revealed that bvFTD patients scored higher on the ACE-III in comparison to the LPA and AD groups (all $p$-values $<0.05$ ), with no further between-patient group differences evident. Performance on the neuropsychological test battery revealed characteristic cognitive profiles in each dementia group in line with their clinical diagnoses (see Supplementary Material). Finally, carer-reported burden on the ZBI revealed an overall group effect $(F(4,72)=3.500 ; p=0.011)$ driven by elevated carer burden in the bvFTD relative to PNFA carers, with no other group differences. 
Table 1. Demographic and clinical characteristics of the study sample.

\begin{tabular}{|c|c|c|c|c|c|c|c|c|}
\hline Demographics & $\begin{array}{c}\text { LPA } \\
(n=12)\end{array}$ & $\begin{array}{c}\text { SD } \\
(n=11)\end{array}$ & $\begin{array}{l}\text { PNFA } \\
(n=9)\end{array}$ & $\begin{array}{c}\mathrm{AD} \\
(n=19)\end{array}$ & $\begin{array}{l}\text { bvFTD } \\
(n=26)\end{array}$ & $\begin{array}{l}\text { Control } \\
(n=31)\end{array}$ & $F$-Test & Post Hoc \\
\hline Age (y) & $69.8(7.0)$ & $63.8(6.2)$ & $67.1(6.1)$ & $66.1(7.6)$ & $64.8(5.8)$ & $65.4(6.3)$ & NS & - \\
\hline Education (y) & 11.9 (3.5) & $13.8(2.3)$ & $12.4(3.2)$ & $13.2(3.7)$ & $12.1(3.7)$ & 13.9 (3.7) & NS & - \\
\hline Sex (M:F) & $7: 5$ & $7: 4$ & $2: 7$ & 10:9 & 19:7 & $16: 15$ & NS & - \\
\hline $\begin{array}{c}\text { Disease } \\
\text { Duration (y) }\end{array}$ & $5.2(2.5)$ & $6.7(2.9)$ & $6.1(3.0)$ & $7.2(5.1)$ & $7.5(4.7)$ & - & NS & - \\
\hline $\begin{array}{l}\text { ACE-III Total } \\
\text { (100) }\end{array}$ & $63.7(17.1)$ & $71.1(21.7)$ & $80.0(16.1)$ & $69.6(12.5)$ & $82.8(9.3)$ & $94.1(3.8)$ & $* * *$ & $\mathrm{CN}>$ Patients \\
\hline $\begin{array}{l}\text { FRS (Rasch } \\
\text { score) }\end{array}$ & $0.85(1.4)$ & $0.82(1.4)$ & $2.7(1.8)$ & $0.42(1.1)$ & $-0.38(1.3)$ & - & $* * *$ & $\begin{array}{c}\text { PNFA > AD } \\
\text { bvFTD }\end{array}$ \\
\hline ZBI (48) & $13.2(6.8)$ & 18.7 (8.7) & $11.4(6.5)$ & $15.2(8.7)$ & $21.4(10.0)$ & - & * & bvFTD $>$ PNFA \\
\hline
\end{tabular}

Notes: Means with standard deviations in parentheses. $\mathrm{AD}=$ Alzheimer's disease; bvFTD = behavioural variant of frontotemporal dementia; $\mathrm{CN}$ = controls; $\mathrm{LPA}=$ logopenic progressive aphasia; $\mathrm{PNFA}=$ progressive non-fluent aphasia; $(\mathrm{y})=$ years; $\mathrm{ZBI}=\mathrm{Zarit}$ Burden Interview. ${ }^{*} p<0.05 ; * * * p<0.0001 ;-=$ not applicable; NS = not significant. Education data available for 28 controls. Disease duration available for $15 \mathrm{AD}$. ACE-III data available for 29 controls. FRS data available for 14 AD and 20 bvFTD.

\subsection{LCQ Performance}

\subsubsection{Overall Social Communication Deficits}

Figure 1 and Table 2 display the results of the performance on the LCQ. A univariate ANOVA revealed a significant main effect of group on the LCQ $(F(5,102)=8.788, p<0.0001$; $\left.\eta_{p}{ }^{2}=0.301\right)$. Games-Howell post hoc tests confirmed significantly higher LCQ total scores, indicating an overall reduction in social communication efficacy across the majority of patient groups relative to controls (bvFTD: $p<0.0001$; AD: $p=0.001$; SD: $p=0.007$; PNFA: $p=0.013$; LPA: $p=0.067$ ) but no difference between the patient groups (all $p$-values $>0.5$ ).

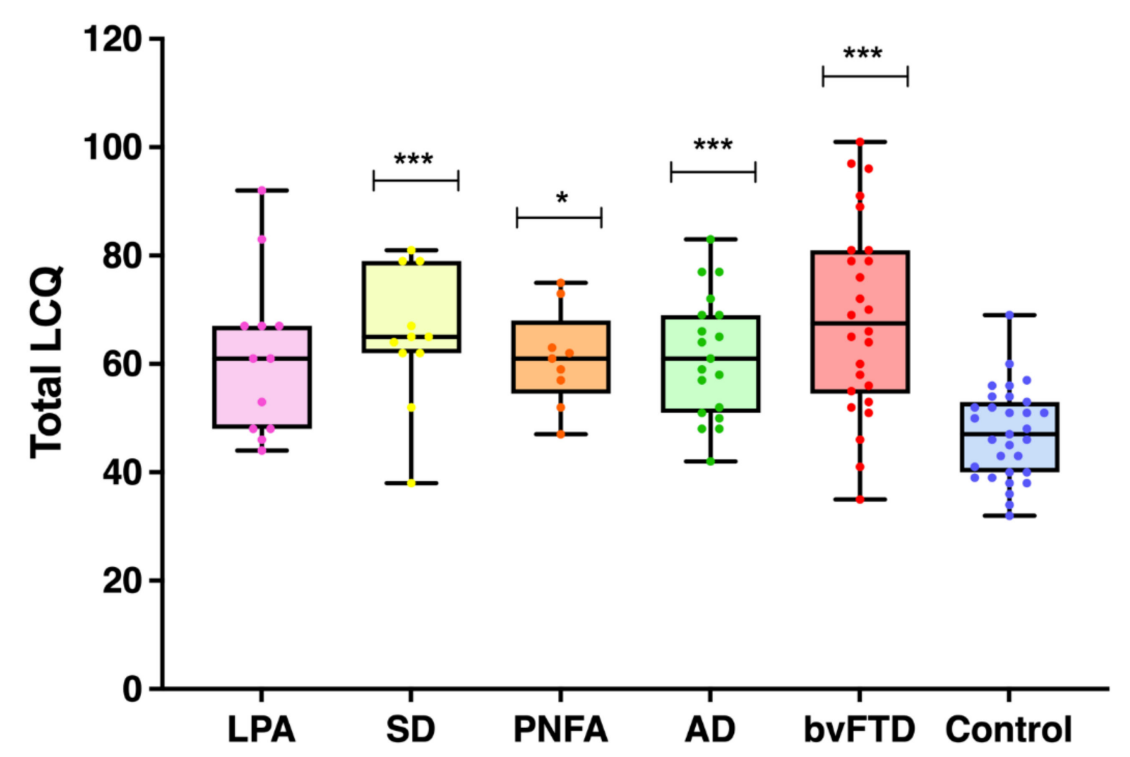

Figure 1. Distribution of total scores on the La Trobe Communication Questionnaire for all groups. Higher scores indicate greater social communication deficits. Asterisks denote significant group differences in relation to control scores. ${ }^{*} p<0.005,{ }^{* * *} p<0.001$. Dots represent individual data points. Error bars represent minimum to maximum values. 
Table 2. Breakdown of social communication difficulties on the La Trobe Communication Questionnaire.

\begin{tabular}{|c|c|c|c|c|c|c|c|c|}
\hline LCQ Score & $\begin{array}{c}\text { LPA } \\
(n=12)\end{array}$ & $\begin{array}{c}\text { SD } \\
(n=11)\end{array}$ & $\begin{array}{l}\text { PNFA } \\
(n=9)\end{array}$ & $\begin{array}{c}\mathrm{AD} \\
(n=19)\end{array}$ & $\begin{array}{l}\text { bvFTD } \\
(n=26)\end{array}$ & $\begin{array}{l}\text { Control } \\
(n=31)\end{array}$ & F-Test & Post Hoc \\
\hline Total (120) & $61.4(15.0)$ & $64.9(12.5)$ & $61.0(9.0)$ & $61.5(11.4)$ & $68.6(17.8)$ & $47.1(8.4)$ & $* * *$ & $\begin{array}{c}\mathrm{CN}<\mathrm{LPA}, \\
\mathrm{SD}, \mathrm{AD}, \\
\text { bvFTD }\end{array}$ \\
\hline Initiation/Flow & $22.0(6.1)$ & $21.6(6.0)$ & $22.8(4.2)$ & $19.3(4.6)$ & $23.2(7.6)$ & $14.5(3.2)$ & $* * *$ & $\begin{array}{c}\mathrm{CN}< \\
\text { Patients }\end{array}$ \\
\hline Disinhibition & $12.3(3.3)$ & $13.7(3.0)$ & $12.2(2.4)$ & $12.5(3.8)$ & $15.0(4.6)$ & $11.1(2.3)$ & $* *$ & $\begin{array}{c}\mathrm{CN}< \\
\text { bvFTD }\end{array}$ \\
\hline $\begin{array}{l}\text { Conversational } \\
\text { Effectiveness }\end{array}$ & $13.4(4.3)$ & $14.7(4.3)$ & $13.9(2.2)$ & $14.6(3.2)$ & $13.7(4.2)$ & $10.8(3.6)$ & $* *$ & $\mathrm{CN}<\mathrm{AD}$ \\
\hline $\begin{array}{l}\text { Partner } \\
\text { Sensitivity }\end{array}$ & $7.9(2.9)$ & $8.6(2.5)$ & $7.2(1.7)$ & $9.2(2.7)$ & $9.9(3.2)$ & $6.7(1.6)$ & $* * *$ & $\begin{array}{c}\mathrm{CN}<\mathrm{AD}, \\
\text { bvFTD }\end{array}$ \\
\hline
\end{tabular}

Notes: Scores presented as means, with standard deviations in parentheses. The maximum test score provided in brackets, where higher scores denote poorer social communication function. $\mathrm{AD}=$ Alzheimer's disease; bvFTD = behavioural variant of frontotemporal dementia; $\mathrm{CN}$ = controls; LCQ = La Trobe Communication Questionnaire; LPA = logopenic progressive aphasia; PNFA = progressive non-fluent aphasia. ${ }^{* * *} p<0.0001 ;{ }^{* *} p<0.01$.

\subsubsection{Social Communication Profiles across Patient Groups}

Looking across the LCQ subscales, a MANOVA revealed an overall effect of group on the following domains: Initiation/Conversational flow $(F(5,102)=8.824, p<0.0001$, $\left.\eta_{p}^{2}=0.302\right)$, Disinhibition/Impulsivity $\left(F(5,102)=4.058, p=0.002, \eta_{p}^{2}=0.166\right)$, Conversational Effectiveness $\left(F(5,102)=3.484, p=0.006, \eta_{p}{ }^{2}=0.146\right)$ and Partner Sensitivity $\left(F(5,102)=5.431, p<0.0001, \eta_{p}^{2}=0.210\right)$.

Games-Howell post hoc tests revealed distinct social communication profiles in each patient group relative to controls (Table 2; Figure 2). Within the PPA cohort, the predominant social communication impairment reported by carers was that of reduced Initiation/Conversational flow on the LCQ. Relative to controls, LPA $(p=0.014)$ and PNFA $(p=0.002)$ were rated as displaying significantly impaired Initiation/Conversational flow in the context of relatively intact Disinhibition/Impulsivity, Conversational Effectiveness and Partner Sensitivity. A similar profile was evident for the SD group, with significantly compromised Initiation/Conversational flow $(p=0.028)$ as well as the suggestion of reduced Conversational Effectiveness $(p=0.058)$. AD patients were rated as significantly impaired in terms of Initiation/Conversational flow $(p=0.006)$, Conversational Effectiveness $(p=0.014)$ and Partner Sensitivity $(p=0.014)$, with no significant impairments in terms of Disinhibition/Impulsivity $(p=0.70)$. In contrast, bvFTD patients were rated as displaying impairments in Initiation/Conversational flow $(p<0.0001)$, Disinhibition/Impulsivity $(p=0.004)$ and Partner Sensitivity $(p=0.001)$, with relatively spared Conversational Effectiveness $(p=0.068)$.

\subsubsection{Correlations with Cognitive Function}

One-tailed Pearson's correlation analyses were run to explore associations between overall communication dysfunction and cognitive function in each patient group separately. Negative associations denote a significant relationship between cognitive decline and increased communication dysfunction on the LCQ total score. Considering the PPA syndromes first, LPA overall communication difficulties were negatively associated with global cognitive function (ACE-III total: $r=-0.617$ and $p=0.016$ ), as well as single-word repetition $(r=-0.549 ; p=0.040)$, semantic association $(r=-0.689 ; p=0.010)$ and comprehension $(r=-0.559 ; p=0.037)$ on the SYDBAT. Similarly in SD, significant negative associations were evident between LCQ total and single-word repetition $(r=-0.750$; $p=0.010)$, semantic association $(r=-0.557 ; p=0.038)$ and comprehension $(r=-0.568$; $p=0.034)$. In contrast, PNFA total LCQ was significantly associated with overall cognitive dysfunction (ACE-III total: $r=-0.757 ; p=0.009$ ). Collectively, these findings indicate 
that, unsurprisingly, social communication disruption is largely associated with overall language decline in PPA syndromes.

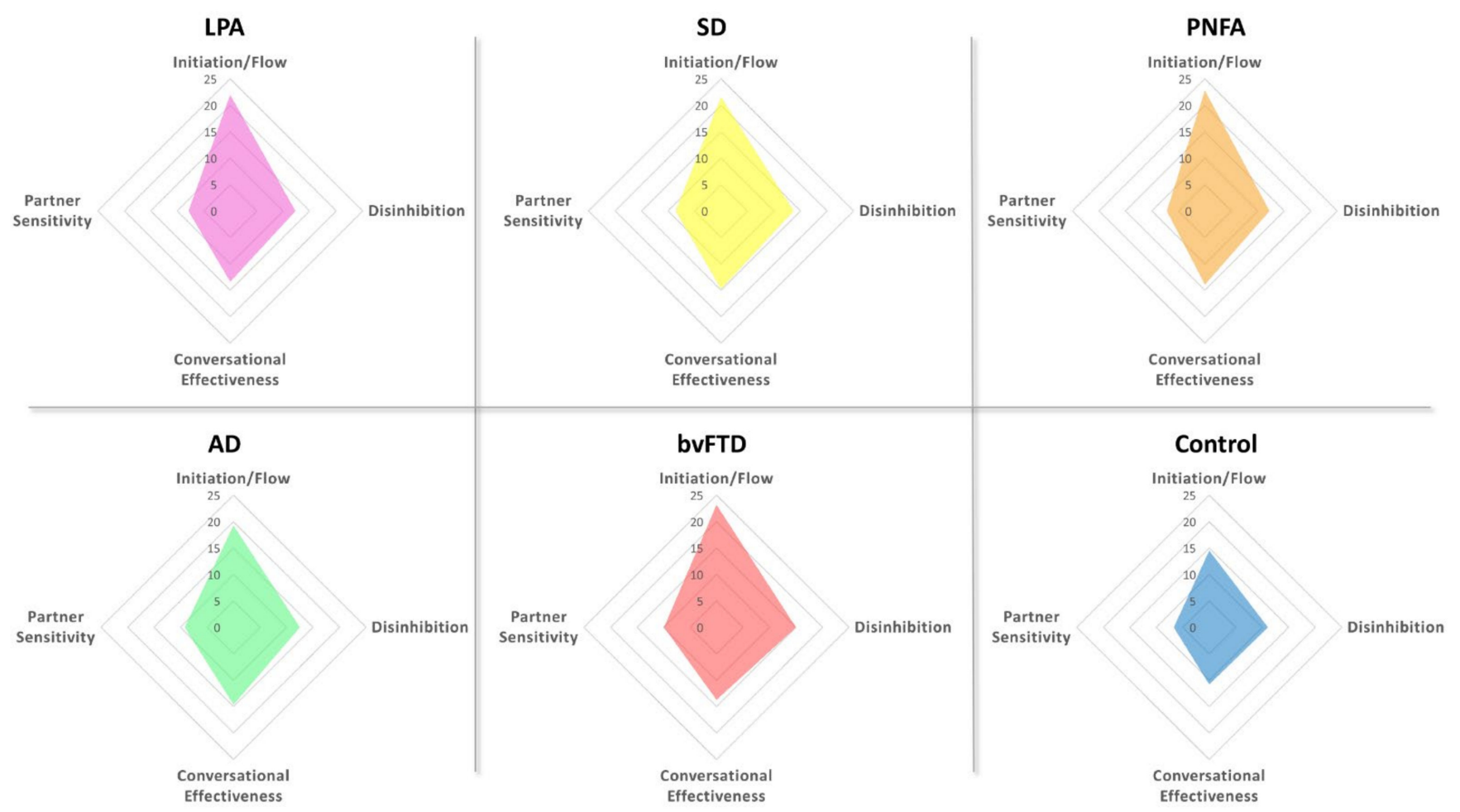

Figure 2. Radar charts showing social communication profiles on the La Trobe Communication Questionnaire subscales for each participant group. Higher scores indicate greater social communication deficits on that dimension.

In $\mathrm{AD}$, total LCQ was found to correlate exclusively with single-word repetition (SYDBAT: $r=-0.525$ and $p=0.013$ ), while in bvFTD, significant associations were found between total LCQ and cognitive function (ACE-III total: $r=-0.391 ; p=0.024$ ), single-word repetition (SYDBAT: $r=-0.552 ; p=0.009$ ) and response inhibition (Hayling Total Cat A errors: $r=0.361 ; p=0.045)$.

\subsubsection{Relationship between Social Communication Dysfunction and Carer Burden}

One-tailed partial correlation analyses were run to explore the relationship between overall social communication dysfunction on the LCQ and patient functional outcomes on the FRS as well as carer-reported burden on the ZBI, controlling for overall disease duration. In LPA, social communication dysfunction was found to correlate with level of functional impairment on the FRS $(r=-0.701 ; p=0.008)$ but not with carer burden on the ZBI $(r=0.296 ; p=0.189)$. The same profile of associations was observed in the PNFA group, whereby LCQ total was associated with functional impairment (FRS: $r=-0.719 ; p=0.022$ ) but not with carer burden (ZBI: $r=0.507 ; p=0.100$ ). In contrast, LCQ correlated robustly with functional impairment (FRS: $r=-0.806 ; p=0.002$ ) and carer burden (ZBI: $r=0.811$; $p=0.002$ ) in the SD group. The same pattern of associations was evident in bvFTD (FRS: $r=-0.677 ; p=0.001$ and ZBI: $r=0.721 ; p<0.0001)$, while no significant associations were found in $\mathrm{AD}$ (all $p$-values $>0.070$ ).

\subsection{Neuroimaging Analyses}

Regions of decreased grey matter intensity associated with higher total scores on the LCQ are presented in Table 3 and Figure 3. The overall severity of social communication dysfunction was associated with grey matter intensity decrease in a discrete set of regions, including the right orbitofrontal cortex extending into the insular cortex, the right inferior frontal gyrus, the right frontal pole, and the left thalamus. 
Table 3. Grey matter correlates of perceived social communication dysfunction across the entire study cohort $(n=79)$.

\begin{tabular}{|c|c|c|c|c|c|c|c|}
\hline \multirow[t]{2}{*}{ Contrast } & \multirow[t]{2}{*}{ Regions } & \multirow[t]{2}{*}{ Side } & \multirow[t]{2}{*}{$\begin{array}{l}\text { Cluster } \\
\text { Size }\end{array}$} & \multicolumn{3}{|c|}{$\begin{array}{c}\text { Cluster Peak } \\
\text { MNI Coordinates }\end{array}$} & \multirow[t]{2}{*}{$t$-Value } \\
\hline & & & & $\mathrm{x}$ & $\mathrm{y}$ & $\mathrm{z}$ & \\
\hline \multirow[t]{3}{*}{$\begin{array}{l}\text { LCQ } \\
\text { Total }\end{array}$} & $\begin{array}{l}\text { Orbitofrontal cortex, } \\
\text { insular cortex, inferior } \\
\text { frontal gyrus }\end{array}$ & $\mathrm{R}$ & 204 & 44 & 32 & -6 & 3.20 \\
\hline & Thalamus & $\mathrm{L}$ & 113 & -16 & -16 & 6 & 3.09 \\
\hline & Frontal pole & $\mathrm{R}$ & 57 & 32 & 64 & 2 & 2.67 \\
\hline
\end{tabular}

Notes: Age was included as a nuisance variable in all contrasts. Clusters are reported voxel-wise, corrected for a false discovery rate of $q=0.05$ (corrected $p=0.03$ ) and a cluster extent threshold of 50 contiguous voxels. MNI = Montreal Neurological Institute; $\mathrm{L}=$ left; $\mathrm{R}=$ right.

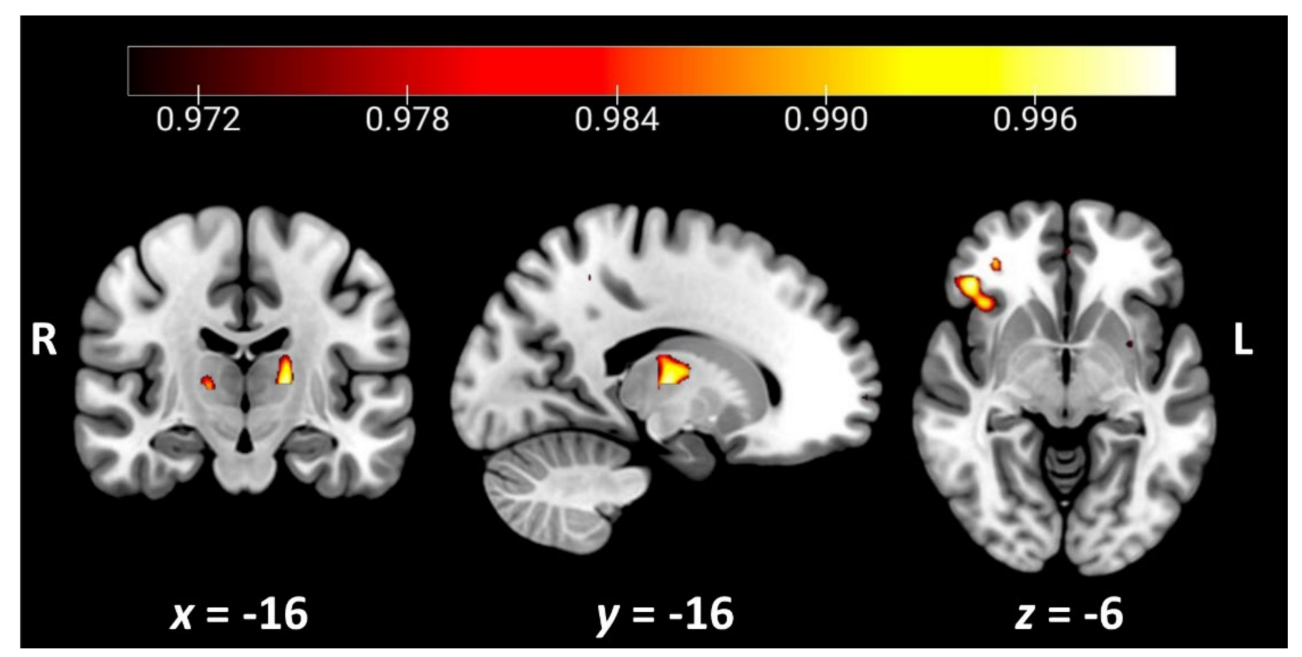

Figure 3. Grey matter correlates of overall social communication dysfunction on the LCQ total across the entire study cohort $(n=79)$. Coloured voxels indicate regions that emerged as significant in the voxel-based morphometry analyses, extracted voxel-wise and corrected for a false discovery rate of $q=0.05$ (corrected $p<0.03$ ). All clusters reported $t>2.67$. Age was included as a nuisance variable in the analyses. Clusters are overlaid on the Montreal Neurological Institute (MNI) standard brain with $x$ - and $y$-coordinates reported in the MNI standard space. $\mathrm{L}=$ left; $\mathrm{R}=$ right. Figures created using MRIcroGL.

\section{Discussion}

The objective of this study was to explore multidimensional profiles of social communication in PPA using the La Trobe Communication Questionnaire (LCQ) and to identify potential cognitive and neural mechanisms driving these changes. Overall, distinct changes in social communication were observed in PNFA and SD, with a trend towards impairment in the LPA group. These deficits reflect a decline in pragmatics and the use of language, both verbal and non-verbal, in social contexts. Deficits in social communication of the same magnitude as that displayed in PPA were also observed in the AD and bvFTD groups, suggesting that a breakdown in socioemotional aspects of communication may be a transdiagnostic feature of neurodegenerative disorders. Looking at specific social communication profiles, initiation and conversational flow were found to be uniformly impaired irrespective of dementia subtype and may reflect a domain-general marker of dementia. Despite this shared feature, disease-specific impairments emerged across the LCQ subscales, suggesting that the canonical language and speech production disturbances displayed by PPA patients on formal clinical assessment manifest in variable ways in their everyday discourse.

Considering first the PPA syndromes, PNFA and LPA were reported to display significant impairments exclusively in initiation and conversational flow. This finding is largely 
in keeping with the canonical motor speech disturbances in PNFA and word-finding difficulty and conversational lapses characteristic of LPA [2]. While overall communication difficulties were associated with degree of cognitive impairment on the ACE-III in both groups, LPA social communication difficulties were also associated with indices of language dysfunction, including single-word repetition, semantic association and semantic comprehension. These differential correlations speak to the multifaceted nature of social communication changes in PPA and the fact that behaviourally similar profiles can emerge due to the breakdown of distinct underlying cognitive, linguistic and motoric processes.

Interestingly, we did not find significant associations between overall social communication dysfunction and perceived burden in carers of LPA or PNFA patients; however, robust correlations were found with functional impairment in both syndromes. Accordingly, while social communication difficulties impinge negatively on everyday functional activities in these patients, they do not appear to be viewed as burdensome by carers and may reflect their relatively preserved capacity to connect socially in certain domains. The experience of PPA has been shown to vary widely depending on subtype and patient/carer perspective, whereby individuals with PPA tend to focus on language decline while family members concentrate their efforts on adapting to and managing socioemotional and behavioural changes [57]. When viewed in this light, the types of communication dysfunction assessed by the LCQ are likely to be anticipated by carers as part of the typical disease trajectory in PNFA and LPA and perceived as more manageable. What remains unclear is how these changes impact the patient's lived experience and sense of self [58], and we suggest that this is a critical area for future empirical research.

Turning our attention to the communication profile of SD, we found evidence of disrupted initiation and conversational flow, with a trend towards reduced conversational effectiveness in this syndrome (see also [59]). Intuitively, these features make sense within the overall cognitive landscape of SD, which is dominated by the deterioration of core semantic processes that are central to the production of content-rich speech [60]. Previous studies suggest prominent changes in the content of narrative discourse in SD, with patients defaulting to the present tense and less complex narrative structure during autobiographical narration [61]. Moreover, with worsening semantic impairment, SD patients have been observed to become increasingly rigid in terms of their preferences, behaviours, and creative problem-solving capacity [62-64]. It remains unclear how the progressive narrowing of the conceptual knowledge space impacts topic selection and maintenance during natural discourse. However, our correlation analyses indicated significant associations between overall social communication dysfunction in SD and independent clinical assessments of semantic processing. In contrast to PNFA and LPA, the impact of social communication disturbances in SD was evident both in terms of patient functional impairment and level of carer burden. This finding resonates strongly with a recent qualitative review of the lived experience in PPA in which carers of SD reported higher levels of perceived burden, which were largely driven by behavioural changes and rigidity in this syndrome [57]. Reduced conversational effectiveness in SD due to hallmark features of anomia and circumlocutions may be perceived by carers as topic derailment or oppositional behaviour (see also [19]). This proposal dovetails with findings of off-target verbosity during autobiographical narration in SD, where patients default to personally relevant and familiar topics drawn from their intact episodic memory store [65-67], inadvertently compromising the effectiveness of their interactions. Emotion recognition may also play an important modulating role in this context, as studies suggest that verbosity in older age may, in part, reflect an inability to decode emotional cues of the listener [68]. Changes in emotion processing and empathy are increasingly recognised in SD and have been shown to impact negatively on the quality of the patient-carer relationship $[11,19,20,69]$. It remains unclear how emotion processing difficulties relate to social communication changes in SD. However, given the negative impact of social communication dysfunction on patient and carer outcomes, this represents an important area for future study to inform targeted interventions. 
Disease-specific changes in social communication were also evident in the non-PPA syndromes. Briefly, in addition to impaired initiation and conversational flow, AD patients displayed reduced conversational effectiveness and partner sensitivity. On the surface, reduced partner sensitivity would appear somewhat at odds with reports of relatively intact socioemotional processing in AD, at least in the early stages of the disease course $[19,70]$. Closer inspection of the partner sensitivity index, however, reveals items that likely tax dynamic aspects of conversational discourse related to episodic and working memory functions, manifesting in repetitive content and topic switching that could be perceived as insensitive to the conversational partner. Importantly, despite carers rating an increase in social communication difficulties in $\mathrm{AD}$, this was not associated with functional impairment in patients or with perceived burden in carers. In contrast, patients with bvFTD were reported to display disinhibition and diminished partner sensitivity alongside impaired initiation and conversational flow. These disturbances are in keeping with the profound socioemotional impairments in empathy, theory of mind, emotion processing and stimulusbound thinking that typify the bvFTD syndrome [22,71-73]. While bvFTD patients do not display an obvious aphasia, they do display difficulties with prosody, comprehension and expression of abstract words and narratives [74]. Collectively, these cognitive and social comportment changes impact dramatically on the capacity to engage effectively in conversational discourse and may compound aspects of functional decline and carer burden in this syndrome.

A secondary aim of this study was to explore the potential underlying neural substrates of social communication changes in dementia using a transdiagnostic approach. Our voxel-based morphometry analyses revealed significant associations between increased social communication disturbances and grey matter intensity decrease in discrete cortical and subcortical regions, including right-sided orbitofrontal and insular cortices, inferior frontal gyrus, and the left thalamus. The finding of significant right-sided orbitofrontal and frontoinsular cortical involvement resonates with an expansive literature implicating these structures in complex cognitive, affective and interoceptive processes that are essential for higher-level social cognitive functioning and behavioural regulation [75,76], as well as for assigning value to stimuli and in reward processing broadly $[77,78]$. These regions exhibit strong connections to the inferior frontal gyrus, which supports attentional control, response inhibition and aspects of speech and social cognitive function [79] and emerged as a significant neural correlate in our analyses. Finally, we found evidence of significant thalamic involvement, resonating with an emerging literature in which the thalamus is viewed as making an important contribution to cognition [80]. Mounting reports indicate that rather than being a passive relay station, the thalamus is actively involved in integrative cognitive processes, including learning and memory, flexible adaptation, and the shaping of mental representations [81]. Our findings, therefore, suggest that disruption of a right-sided cortico-thalamic circuit may contribute to social communication disturbances seen across dementia syndromes.

A number of methodological considerations and future directions warrant discussion. First, our sample size is relatively small, reflecting the rarity of the PPA syndromes of interest. Our findings warrant replication in a larger cohort ideally stratified by disease staging and symptom severity to understand the prevalence and timing of these social communication difficulties. Second, while informant-based questionnaires are a useful tool to examine the inherently collaborative nature of social communication, it is imperative to understand the lived experience of the patient in this regard. A limitation of our study is that we compared carer reports for patients with self-reports for controls. Ideally, future studies should collect self-ratings and informant ratings of social communication for all participants to ensure the comparability of findings. A key issue will be to determine whether these changes in social communication represent a source of stress for the patient and the extent to which these changes are disruptive in terms of the functional goals of communication. Future studies could complement the data provided by the LCQ by incorporating naturalistic discourse assessments to determine the experience of patients when 
engaging in communication across different social settings. In this regard, conversation analysis may prove particularly fruitful in providing direct insights into the social communication profiles of people with PPA, as well as the evolution of these profiles over time. Given mounting evidence of distinct cognitive and behavioural trajectories with advancing disease severity in PPA $[7,82]$, longitudinal studies will provide crucial information to inform the nature of therapeutic support required by patients over time. In addition, it will be important for future studies to explore how impairments in social cognitive processes, such as theory of mind, empathy, and mental simulation, are potentially impacted by, and interact with, canonical language disturbances in dementia syndromes. Similarly, an interesting further consideration is whether motivational disturbances mediate changes in social communication, given emerging evidence of apathy (i.e., decreased goal-directed behaviour) and anhedonia (i.e., decreased interest in and response to rewarding experiences) in PPA [83-86]. Whether patients with dementia become less motivated to engage in activities involving social communication represents an unanswered question that will be crucial to address prior to trialling interventions.

\section{Conclusions}

In summary, we have provided evidence of social communication disruption in PPA and non-PPA syndromes, with variable profiles of social communication observed across the patient groups. Our findings hold a number of important clinical implications. While PPA syndromes predominantly displayed impaired initiation and conversational flow, partner sensitivity and disinhibition did not seem to be compromised. Understanding such profiles of loss and sparing in conversational discourse is important to identifying potential strategies to support patient-carer communication and alleviate stress or burden associated with these changes [87]. For example, communication training programs have been successfully implemented to improve turn-taking and decrease verbosity during conversational discourse in patients with traumatic brain injury (TBI, e.g., [88]). Similarly, communication partner training programmes have been shown to provide an effective means of targeting distinct aspects of communication in various neurological disorders, including stroke, TBI, and dementia [89,90]. Translating such approaches for use in the PPA setting will, therefore, be an important future direction for this research.

Supplementary Materials: The following are available online at https:/ /www.mdpi.com/article/10 .3390/brainsci11121600/s1: Table S1: Cognitive performance across neuropsychological domains of interest; Table S2: Profiles of grey matter intensity decrease in patient groups relative to controls.

Author Contributions: Conceptualisation, Z.-L.G. and M.I.; data curation, R.M.A.; formal analysis, Z.-L.G., H.E.-O. and M.I.; funding acquisition, O.P. and M.I.; methodology, Z.-L.G. and M.I.; resources, O.P.; supervision, M.I.; writing—original draft preparation, Z.-L.G. and M.I.; writing—review and editing, H.E.-O., D.F., C.E.L., R.M.A. and O.P. All authors have read and agreed to the published version of the manuscript.

Funding: This study was supported in part by funding to ForeFront, a large collaborative research group dedicated to the study of neurodegenerative diseases, from the National Health and Medical Research Council (NHMRC) Program Grant (GNT1132524) and Dementia Research Team Grant (GNT1095127), as well as the Australian Research Council (ARC) Centre of Excellence in Cognition and Its Disorders (CE11000102). The authors acknowledge the technical assistance provided by the Sydney Informatics Hub, a core research facility of the University of Sydney. C.E.L. is supported by an NHMRC Dementia Research Development Fellowship (GNT1102969). O.P. is supported by an NHMRC Senior Research Fellowship (GNT1103258). M.I. is supported by an ARC Future Fellowship (FT160100096). These funding sources were not involved in the study design, in the collection, analysis and interpretation of data, in the writing of the report or in the decision to submit the manuscript for publication.

Institutional Review Board Statement: This study was conducted according to the guidelines of the Declaration of Helsinki and approved by the University of New South Wales and the South Eastern Sydney Local Health District human ethics committee (Approval: HREC 10-126; HREC 13-177). 
Informed Consent Statement: Informed consent was obtained from all subjects involved in the study. Written informed consent was obtained from the patient(s) to publish this paper.

Data Availability Statement: The ethical requirement to ensure patient confidentiality precludes public archiving of our data. Researchers who would like to access the raw data should contact the corresponding author, who will liaise with the ethics committee that approved the study. Accordingly, as much data as are required to reproduce the results will be released to the individual researcher. No parts of the study procedures or analyses were registered prior to the research being undertaken.

Acknowledgments: The authors are grateful to the research participants involved with the ForeFront research studies. We wish to thank Angela Scharfenberg, Sau Chi Cheung, Sarah Carnemolla and Samuel Stark for their research assistance.

Conflicts of Interest: The authors report no conflict of interest.

\section{References}

1. Gorno-Tempini, M.L.; Hillis, A.E.; Weintraub, S.; Kertesz, A.; Mendez, M.; Cappa, S.F.; Ogar, J.M.; Rohrer, J.D.; Black, S.; Boeve, B.F.; et al. Classification of primary progressive aphasia and its variants. Neurology 2011, 76, 1006-1014. [CrossRef]

2. Marshall, C.R.; Hardy, C.J.D.; Volkmer, A.; Russell, L.L.; Bond, R.L.; Fletcher, P.D.; Clark, C.N.; Mummery, C.J.; Schott, J.M.; Rossor, M.N.; et al. Primary progressive aphasia: A clinical approach. J. Neurol. 2018, 265, 1474-1490. [CrossRef]

3. Tippett, D.C. Classification of primary progressive aphasia: Challenges and complexities. F1000Research 2020, 9, 1-9. [CrossRef]

4. Sajjadi, S.A.; Patterson, K.; Arnold, R.J.; Watson, P.C.; Nestor, P.J. Primary progressive aphasia: A tale of two syndromes and the rest. Neurology 2012, 78, 1670-1677. [CrossRef]

5. Croot, K.; Ballard, K.; Leyton, C.E.; Hodges, J.R. Apraxia of speech and phonological errors in the diagnosis of nonfluent/agrammatic and logopenic variants of primary progressive aphasia. J. Speech Lang. Hear. Res. 2012, 55, S1562-S1572. [CrossRef]

6. Foxe, D.; Cheung, S.C.; Cordato, N.J.; Burrell, J.R.; Ahmed, R.M.; Taylor-Rubin, C.; Irish, M.; Piguet, O. Verbal short-term memory disturbance in the primary progressive aphasias: Challenges and distinctions in a clinical setting. Brain Sci. 2021, 11, 1060. [CrossRef]

7. Foxe, D.; Irish, M.; Hu, A.; Carrick, J.; Hodges, J.R.; Ahmed, R.M.; Burrell, J.R.; Piguet, O. Longitudinal cognitive and functional changes in primary progressive aphasia. J. Neurol. 2021, 268, 1951-1961. [CrossRef]

8. Butts, A.M.; Machulda, M.M.; Duffy, J.R.; Strand, E.A.; Whitwell, J.L.; Josephs, K.A. Neuropsychological profiles differ among the three variants of primary progressive aphasia. J. Int. Neuropsychol. Soc. 2015, 21, 429-435. [CrossRef] [PubMed]

9. Ramanan, S.; Roquet, D.; Goldberg, Z.L.; Hodges, J.R.; Piguet, O.; Irish, M.; Lambon Ralph, M.A. Establishing two principal dimensions of cognitive variation in logopenic progressive aphasia. Brain Commun. 2020, 2, fcaa125. [CrossRef] [PubMed]

10. Fittipaldi, S.; Ibanez, A.; Baez, S.; Manes, F.; Sedeno, L.; Garcia, A.M. More than words: Social cognition across variants of primary progressive aphasia. Neurosci. Biobehav. Rev. 2019, 100, 263-284. [CrossRef] [PubMed]

11. Kumfor, F.; Irish, M.; Hodges, J.R.; Piguet, O. Discrete neural correlates for the recognition of negative emotions: Insights from frontotemporal dementia. PLoS ONE 2013, 8, e67457.

12. Rohrer, J.D.; Sauter, D.; Scott, S.; Rossor, M.N.; Warren, J.D. Receptive prosody in nonfluent primary progressive aphasias. Cortex 2012, 48, 308-316. [CrossRef]

13. Hazelton, J.L.; Irish, M.; Hodges, J.R.; Piguet, O.; Kumfor, F. Cognitive and affective empathy disruption in non-fluent primary progressive aphasia syndromes. Brain Impair. 2016, 18, 117-129. [CrossRef]

14. Kamminga, J.; Kumfor, F.; Burrell, J.R.; Piguet, O.; Hodges, J.R.; Irish, M. Differentiating between right-lateralised semantic dementia and behavioural-variant frontotemporal dementia: An examination of clinical characteristics and emotion processing. J. Neurol Neurosurg. Psychiatry 2015, 86, 1082-1088. [CrossRef] [PubMed]

15. Piguet, O.; Leyton, C.E.; Gleeson, L.D.; Hoon, C.; Hodges, J.R. Memory and emotion processing performance contributes to the diagnosis of non-semantic primary progressive aphasia syndromes. J. Alzheimers Dis. 2015, 44, 541-547. [CrossRef]

16. Irish, M.; Hodges, J.R.; Piguet, O. Right anterior temporal lobe dysfunction underlies theory of mind impairments in semantic dementia. Brain 2014, 137, 1241-1253. [CrossRef] [PubMed]

17. Duval, C.; Bejanin, A.; Piolino, P.; Laisney, M.; de La Sayette, V.; Belliard, S.; Eustache, F.; Desgranges, B. Theory of mind impairments in patients with semantic dementia. Brain 2012, 135 Pt 1, 228-241. [CrossRef]

18. Couto, B.; Manes, F.; Montanes, P.; Matallana, D.; Reyes, P.; Velasquez, M.; Yoris, A.; Baez, S.; Ibanez, A. Structural neuroimaging of social cognition in progressive non-fluent aphasia and behavioral variant of frontotemporal dementia. Front. Hum. Neurosci. 2013, 7, 467. [CrossRef]

19. Hsieh, S.; Irish, M.; Daveson, N.; Hodges, J.R.; Piguet, O. When one loses empathy: Its effect on carers of patients with dementia. J. Geriatr. Psychiatry Neurol. 2013, 26, 174-184. [CrossRef]

20. Irish, M.; Kumfor, F.; Hodges, J.R.; Piguet, O. A tale of two hemispheres: Contrasting socioemotional dysfunction in right-versus left-lateralised semantic dementia. Dement. Neuropsychol. 2013, 7, 88-95. [CrossRef] [PubMed] 
21. Rankin, K.P.; Gorno-Tempini, M.L.; Allison, S.C.; Stanley, C.M.; Glenn, S.; Weiner, M.W.; Miller, B.L. Structural anatomy of empathy in neurodegenerative disease. Brain 2006, 129 Pt 11, 2945-2956. [CrossRef]

22. Henry, J.D.; von Hippel, W.; Molenberghs, P.; Lee, T.; Sachdev, P.S. Clinical assessment of social cognitive function in neurological disorders. Nat. Rev. Neurol. 2016, 12, 28-39. [CrossRef] [PubMed]

23. Grice, H.P. Studies in the Way of Words; Harvard University Press: Cambridge, MA, USA, 1989.

24. Searle, J.R. What is an intentional state? Mind 1979, 88, 74-92. [CrossRef]

25. Hyter, Y.D. Pragmatic assessment and intervention in children. In Research in Clinical Pragmatics; Cummings, L., Ed.; Springer International Publishing: Cham, Switzerland, 2017; pp. 493-526.

26. Wilson, D. New directions for research on pragmatics and modularity. Lingua 2005, 115, 1129-1146. [CrossRef]

27. Catani, M.; Bambini, V. A model for social communication and language evolution and development (SCALED). Curr. Opin. Neurobiol. 2014, 28, 165-171. [CrossRef]

28. Bambini, V.; Tonini, E.; Ceccato, I.; Lecce, S.; Marocchini, E.; Cavallini, E. How to improve social communication in aging: Pragmatic and cognitive interventions. Brain Lang. 2020, 211, 104864. [CrossRef] [PubMed]

29. Sobral, A.; de Araujo, C.M.T.; Sobral, M.F.F. Mild cognitive impairment in the elderly relationship between communication and functional capacity. Dement. Neuropsychol. 2018, 12, 165-172. [CrossRef]

30. Douglas, J.M.; O'Flaherty, C.A.; Snow, P.C. Measuring perception of communicative ability: The development and evaluation of the La Trobe communication questionnaire. Aphasiology 2000, 14, 251-268. [CrossRef]

31. Blair, M.; Marczinski, C.A.; Davis-Faroque, N.; Kertesz, A. A longitudinal study of language decline in Alzheimer's disease and frontotemporal dementia. J. Int. Neuropsychol. Soc. 2007, 13, 237-245. [CrossRef]

32. Hardy, C.J.; Buckley, A.H.; Downey, L.E.; Lehmann, M.; Zimmerer, V.C.; Varley, R.A.; Crutch, S.J.; Rohrer, J.D.; Warrington, E.K.; Warren, J.D. The language profile of behavioral variant frontotemporal dementia. J. Alzheimers Dis. 2016, 50, 359-371. [CrossRef]

33. Dermody, N.; Wong, S.; Ahmed, R.; Piguet, O.; Hodges, J.R.; Irish, M. Uncovering the neural bases of cognitive and affective empathy deficits in alzheimer's disease and the behavioral-variant of frontotemporal dementia. J. Alzheimers Dis. 2016, 53, 801-816. [CrossRef]

34. Bambini, V.; Arcara, G.; Bechi, M.; Buonocore, M.; Cavallaro, R.; Bosia, M. The communicative impairment as a core feature of schizophrenia: Frequency of pragmatic deficit, cognitive substrates, and relation with quality of life. Compr. Psychiatry 2016, 71, 106-120. [CrossRef] [PubMed]

35. McKhann, G.M.; Knopman, D.S.; Chertkow, H.; Hyman, B.T.; Jack, C.R., Jr.; Kawas, C.H.; Klunk, W.E.; Koroshetz, W.J.; Manly, J.J.; Mayeux, R.; et al. The diagnosis of dementia due to Alzheimer's disease: Recommendations from the National Institute on Aging-Alzheimer's Association workgroups on diagnostic guidelines for Alzheimer's disease. Alzheimers Dement. 2011, 7, 263-269. [CrossRef]

36. Rascovsky, K.; Hodges, J.R.; Knopman, D.; Mendez, M.F.; Kramer, J.H.; Neuhaus, J.; van Swieten, J.C.; Seelaar, H.; Dopper, E.G.; Onyike, C.U.; et al. Sensitivity of revised diagnostic criteria for the behavioural variant of frontotemporal dementia. Brain 2011, 134 Pt 9, 2456-2477. [CrossRef]

37. Mioshi, E.; Hsieh, S.; Savage, S.; Hornberger, M.; Hodges, J.R. Clinical staging and disease progression in frontotemporal dementia. Neurology 2010, 74, 1591-1597. [CrossRef]

38. Bédard, M.; Molloy, D.W.; Squire, L.; Dubois, S.; Lever, J.A.; O’Donnell, M. The Zarit Burden interview a new short version and screening version. Gerontologist 2001, 41, 652-657. [CrossRef] [PubMed]

39. Hsieh, S.; Schubert, S.; Hoon, C.; Mioshi, E.; Hodges, J.R. Validation of the addenbrooke's cognitive examination III in frontotemporal dementia and Alzheimer's disease. Dement. Geriatr. Cogn. Disord. 2013, 36, 242-250. [CrossRef]

40. So, M.; Foxe, D.; Kumfor, F.; Murray, C.; Hsieh, S.; Savage, G.; Ahmed, R.M.; Burrell, J.R.; Hodges, J.R.; Irish, M.; et al. Addenbrooke's cognitive examination III: Psychometric characteristics and relations to functional ability in dementia. J. Int. Neuropsychol. Soc. 2018, 24, 854-863. [CrossRef] [PubMed]

41. Wechsler, D. Wechsler Memory Scale Administration and Scoring Manual, 3rd ed.; Psychological Corporation: San Antonio, TX, USA, 1997.

42. Reitan, R. Validity of the Trail Making Test as an indicator of organic brain damage. Percept. Mot. Ski. 1958, 8, 271-276. [CrossRef]

43. Rey, A. L'examen psychologique dans les cas d'encéphalopathie traumatique. Arch. Psychol. 1941, 28, $215-285$.

44. Irish, M.; Piguet, O.; Hodges, J.R.; Hornberger, M. Common and unique grey matter correlates of episodic memory dysfunction in frontotemporal dementia and Alzheimer's disease. Hum. Brain Mapp. 2014, 35, 1422-1435. [CrossRef] [PubMed]

45. Savage, S.A.; Hsieh, S.; Leslie, F.; Foxe, D.; Piguet, O.; Hodges, J.R. Distinguishing subtypes in primary progressive aphasia: Application of the Sydney language battery. Dement. Geriatr. Cogn. Disord. 2013, 35, 208-218. [CrossRef] [PubMed]

46. Burgess, P.; Shallice, T. (Eds.) The Hayling and Brixton Tests; Thames Valley Test Company: Bury St Edmonds, UK, 1997.

47. Struchen, M.A.; Pappadis, M.R.; Mazzei, D.K.; Clark, A.N.; Davis, L.C.; Sander, A.M. Perceptions of communication abilities for persons with traumatic brain injury: Validity of the La trobe communication questionnaire. Brain Inj. 2008, 22, 940-951. [CrossRef]

48. Ashburner, J.; Friston, K.J. Voxel-based morphometry-The methods. Neuroimage 2000, 11 Pt 1, 805-821. [CrossRef] [PubMed]

49. Smith, S.M.; Jenkinson, M.; Woolrich, M.W.; Beckmann, C.F.; Behrens, T.E.; Johansen-Berg, H.; Bannister, P.R.; De Luca, M.; Drobnjak, I.; Flitney, D.E.; et al. Advances in functional and structural MR image analysis and implementation as FSL. Neuroimage 2004, 23 (Suppl. 1), S208-S219. [CrossRef] 
50. Smith, S.M. Fast robust automated brain extraction. Hum. Brain Mapp. 2002, 17, 143-155. [CrossRef]

51. Zhang, Y.Y.; Brady, M.; Smith, S. Segmentation of brain MR images through a hidden Markov random field model and the expectation-maximization algorithm. IEEE Trans. Med. Imag. 2001, 20, 45-57. [CrossRef]

52. Andersson, J.L.R.; Jenkinson, M.; Smith, S. Non-linear optimisation. In FMRIB Technical Report TR07JA1; University of Oxford FMRIB Centre: Oxford, UK, 2007.

53. Andersson, J.L.R.; Jenkinson, M.; Smith, S. Non-linear registration, aka spatial normalisation. In FMRIB Technical Report TR07JA2; University of Oxford FMRIB Centre: Oxford, UK, 2007.

54. Rueckert, D.; Sonoda, L.I.; Hayes, C.; Hill, D.L.G.; Leach, M.O.; Hawkes, D.J. Nonrigid registration using free-form deformations: Application to breast MR images. IEEE Trans. Med. Imag. 1999, 18, 712-721. [CrossRef]

55. Nichols, T.E.; Holmes, A.P. Nonparametric permutation tests for functional neuroimaging: A primer with examples. Hum. Brain Mapp. 2002, 15, 1-25. [CrossRef]

56. Bennett, C.M.; Wolford, G.L.; Miller, M.B. The principled control of false positives in neuroimaging. Soc. Cogn. Affect. Neurosci. 2009, 4, 417-422. [CrossRef]

57. Davies, K.; Howe, T. Experiences of living with primary progressive aphasia: A scoping review of qualitative studies. Am. J. Alzheimers Dis. Other Demen. 2020, 35, 1533317519886218. [CrossRef] [PubMed]

58. Strikwerda-Brown, C.; Grilli, M.D.; Andrews-Hanna, J.R.; Irish, M. "All is not lost" - Rethinking the nature of memory and the self in dementia. Ageing Res. Rev. 2019, 54, 100932. [CrossRef]

59. Taylor-Rubin, C.; Croot, K.; Power, E.; Savage, S.A.; Hodges, J.R.; Togher, L. Communication behaviors associated with successful conversation in semantic variant primary progressive aphasia. Int. Psychogeriatr. 2017, 29, 1619-1632. [CrossRef]

60. Meteyard, L.; Patterson, K. The relation between content and structure in language production: An analysis of speech errors in semantic dementia. Brain Lang. 2009, 110, 121-134. [CrossRef]

61. Irish, M.; Kamminga, J.; Addis, D.R.; Crain, S.; Thornton, R.; Hodges, J.R.; Piguet, O. "Language of the past"—Exploring past tense disruption during autobiographical narration in neurodegenerative disorders. J. Neuropsychol. 2016, 10, 295-316. [CrossRef]

62. Bozeat, S.; Gregory, C.A.; Ralph, M.A.; Hodges, J.R. Which neuropsychiatric and behavioural features distinguish frontal and temporal variants of frontotemporal dementia from Alzheimer's disease? J. Neurol. Neurosurg. Psychiatry 2000, 69, 178-186. [CrossRef] [PubMed]

63. Paulin, T.; Roquet, D.; Kenett, Y.N.; Savage, G.; Irish, M. The effect of semantic memory degeneration on creative thinking: A voxel-based morphometry analysis. Neuroimage 2020, 220, 117073. [CrossRef]

64. Modirrousta, M.; Price, B.H.; Dickerson, B.C. Neuropsychiatric symptoms in primary progressive aphasia: Phenomenology, pathophysiology, and approach to assessment and treatment. Neurodegener. Dis. Manag. 2013, 3, 133-146. [CrossRef] [PubMed]

65. Irish, M.; Addis, D.R.; Hodges, J.R.; Piguet, O. Considering the role of semantic memory in episodic future thinking: Evidence from semantic dementia. Brain 2012, 135 Pt 7, 2178-2191. [CrossRef]

66. Irish, M.; Addis, D.R.; Hodges, J.R.; Piguet, O. Exploring the content and quality of episodic future simulations in semantic dementia. Neuropsychologia 2012, 50, 3488-3495. [CrossRef]

67. McKinnon, M.; Nica, E.; Sengdy, P.; Kovacevic, N.; Moscovitch, M.; Freedman, M.; Miller, B.; Black, S.; Levine, B. Autobiographical memory and patterns of brain atrophy in fronto-temporal lobar degeneration. J. Cogn. Neurosci. 2008, 20, 1839-1853. [CrossRef]

68. Ruffman, T.; Murray, J.; Halberstadt, J.; Taumoepeau, M. Verbosity and emotion recognition in older adults. Psychol. Aging 2010, 25, 492-497. [CrossRef] [PubMed]

69. Calabria, M.; Cotelli, M.; Adenzato, M.; Zanetti, O.; Miniussi, C. Empathy and emotion recognition in semantic dementia: A case report. Brain Cogn. 2009, 70, 247-252. [CrossRef] [PubMed]

70. Kumfor, F.; Irish, M.; Leyton, C.; Miller, L.; Lah, S.; Devenney, E.; Hodges, J.R.; Piguet, O. Tracking the progression of social cognition in neurodegenerative disorders. J. Neurol. Neurosurg. Psychiatry 2014, 85, 1076-1083. [CrossRef] [PubMed]

71. Strikwerda-Brown, C.; Ramanan, S.; Irish, M. Neurocognitive mechanisms of theory of mind impairment in neurodegeneration: A transdiagnostic approach. Neuropsychiatr. Dis. Treat. 2019, 15, 557-573. [CrossRef] [PubMed]

72. Irish, M.; Piguet, O.; Hodges, J.R. Self-projection and the default network in frontotemporal dementia. Nat. Rev. Neurol. 2012, 8, 152-161. [CrossRef]

73. O'Callaghan, C.; Shine, J.M.; Hodges, J.R.; Andrews-Hanna, J.R.; Irish, M. Hippocampal atrophy and intrinsic brain network dysfunction relate to alterations in mind wandering in neurodegeneration. Proc. Natl. Acad. Sci. USA 2019, 116, $3316-3321$. [CrossRef]

74. Grossman, M. Linguistic aspects of primary progressive aphasia. Annu. Rev. Linguist. 2018, 4, 377-403. [CrossRef]

75. Craig, A.D. How do you feel-now? The anterior insula and human awareness. Nat. Rev. Neurosci. 2009, 10, 59-70. [CrossRef]

76. Kringelbach, M.L.; Rolls, E.T. The functional neuroanatomy of the human orbitofrontal cortex: Evidence from neuroimaging and neuropsychology. Prog. Neurobiol. 2004, 72, 341-372. [CrossRef]

77. Husain, M.; Roiser, J.P. Neuroscience of apathy and anhedonia: A transdiagnostic approach. Nat. Rev. Neurosci. 2018, 19, 470-484. [CrossRef] [PubMed]

78. Ahmed, R.M.; Devenney, E.M.; Irish, M.; Ittner, A.; Naismith, S.; Ittner, L.M.; Rohrer, J.D.; Halliday, G.M.; Eisen, A.; Hodges, J.R.; et al. Neuronal network disintegration: Common pathways linking neurodegenerative diseases. J. Neurol. Neurosurg. Psychiatry 2016, 87, 1234-1241. [CrossRef] [PubMed] 
79. Hartwigsen, G.; Neef, N.E.; Camilleri, J.A.; Margulies, D.S.; Eickhoff, S.B. Functional segregation of the right inferior frontal gyrus: Evidence from coactivation-based parcellation. Cereb. Cortex 2019, 29, 1532-1546. [CrossRef]

80. Saalmann, Y.B.; Kastner, S. The cognitive thalamus. Front. Syst. Neurosci. 2015, 9, 39. [CrossRef]

81. Wolff, M.; Vann, S.D. The cognitive thalamus as a gateway to mental representations. J. Neurosci. 2019, 39, 3-14. [CrossRef] [PubMed]

82. Foxe, D.; Irish, M.; Ramanan, S.; Stark, S.; Cordato, N.J.; Burrell, J.R.; Piguet, O. Longitudinal changes in behaviour, mood, and functional capacity in the primary progressive aphasia variants. Eur. J. Neurosci. 2021. awaiting final decision.

83. Shaw, S.R.; El-Omar, H.; Roquet, D.; Hodges, J.R.; Piguet, O.; Ahmed, R.M.; Whitton, A.E.; Irish, M. Uncovering the prevalence and neural substrates of anhedonia in frontotemporal dementia. Brain 2021, 5, 1551-1564. [CrossRef]

84. Shaw, S.R.; El-Omar, H.; Ramanan, S.; Piguet, O.; Ahmed, R.M.; Whitton, A.E.; Irish, M. Anhedonia in semantic dementiaexploring right hemispheric contributions to the loss of pleasure. Brain Sci. 2021, 11, 998. [CrossRef]

85. Wong, S.; Irish, M.; Husain, M.; Hodges, J.R.; Piguet, O.; Kumfor, F. Apathy and its impact on carer burden and psychological wellbeing in primary progressive aphasia. J. Neurol. Sci. 2020,416, 117007. [CrossRef]

86. Merrilees, J.; Dowling, G.A.; Hubbard, E.; Mastick, J.; Ketelle, R.; Miller, B.L. Characterization of apathy in persons with frontotemporal dementia and the impact on family caregivers. Alzheimer Dis. Assoc. Disord. 2013, 27, 62-67. [CrossRef]

87. Alsawy, S.; Mansell, W.; McEvoy, P.; Tai, S. What is good communication for people living with dementia? A mixed-methods systematic review. Int. Psychogeriatr. 2017, 29, 1785-1800. [CrossRef]

88. Keegan, L.C.; Murdock, M.; Suger, C.; Togher, L. Improving natural social interaction: Group rehabilitation after traumatic brain injury. Neuropsychol. Rehabil. 2020, 30, 1497-1522. [CrossRef] [PubMed]

89. O'Rourke, A.; Power, E.; O'Halloran, R.; Rietdijk, R. Common and distinct components of communication partner training programmes in stroke, traumatic brain injury and dementia. Int. J. Lang. Commun. Disord. 2018, 53, 1150-1168. [CrossRef] [PubMed]

90. Hall, K.; Lind, C.; Young, J.A.; Okell, E.; van Steenbrugge, W. Familiar communication partners' facilitation of topic management in conversations with individuals with dementia. Int. J. Lang. Commun. Disord. 2018, 53, 564-575. [CrossRef] [PubMed] 